\title{
Design and tests of a rotary plug seedling pick-up mechanism for vegetable automatic transplanter
}

\author{
Bingliang Ye ${ }^{1,2}$, Gongjun Zeng ${ }^{1,3}$, Bin Deng ${ }^{1}$, Chiulan Yang ${ }^{4}$, Jikun Liu ${ }^{1}$, Gaohong $\mathrm{Yu}^{1,2} *$ \\ (1. Faculty of Mechanical Engineering \& Automation, Zhejiang Sci-Tech University, Hangzhou 310018, China; \\ 2. Zhejiang Province Key Laboratory of Transplanting Equipment and Technology, Hangzhou 310018, China; \\ 3. Faculty of Mechanical Engineering, Zhejiang Industry Polytechnic College, Shaoxing 312000, China; \\ 4. Faculty of Mechanical Engineering, Chung Yuan Christian University, Taiwan 32023, China)
}

\begin{abstract}
The rotary plug seedling pick-up mechanism for vegetable automatic transplanter is the technical bottleneck to improve the mechanization level of vegetable planting in China. In order to solve the problems of rotary seedling pick-up mechanism proposed in previous study, such as low success ratio of seedling pick-up at high speed, and interference between the seedling bowl and the end of the other seedling pick-up arm, a novel kind of rotary seedling pick-up mechanism of planetary gear train with combined type gears of incomplete denatured-eccentric-circular and non-circular gears was proposed. Through kinematic analysis of the seedling pick-up mechanism, the kinematics model was established. The computer-aided analysis and optimization software with human-computer interaction method was developed to realize parameters optimization of the seedling pick-up mechanism. Three-dimensional parametric design system of seedling pick-up mechanisms with combined non-circular gear transmission was developed for mechanism virtual simulation to verify the correctness of theoretical model and design results of the mechanism. The physical prototype of the mechanism was manufactured, and high-speed camera kinematics tests of the mechanism were conducted in the laboratory to study its kinematic characteristics. Laboratory seedling pick-up tests were carried out. The mechanism has the success ratio of seedling pick-up $96.3 \%$ without interference during seedling transporting when the rotation speed of the mechanism is $50 \mathrm{r} / \mathrm{min}$ and the seedling transplanting efficiency is 100 plants/min per row, showing that the novel mechanism has better working performance than the original one and could be applied in vegetable plug seedling transplanter.
\end{abstract}

Keywords: vegetable automatic transplanter, rotary seedling pick-up mechanism, incomplete denatured-eccentric-circular gear, kinematic analysis, parametric design

DOI: $10.25165 /$ j.ijabe.20201303.5647

Citation: Ye B L, Zeng G J, Deng B, Yang C L, Liu J K, Yu G H. Design and tests of a rotary plug seedling pick-up mechanism for vegetable automatic transplanter. Int J Agric \& Biol Eng, 2020; 13(3): 70-78.

\section{Introduction}

China is the largest vegetables producer and consumer in the world, and the planting areas and yields of vegetable in China account for about $40 \%$ and $50 \%$ of the world's total, respectively. Moreover, the vegetable production will continue to grow in the coming years in China. To accelerate the research of vegetable plug seedling transplanter is very conducive to the mechanization level promotion of dryland economic plant and the rapid development of its industry, which plays an important role in promoting farmers' income and rural economic transformation ${ }^{[1]}$.

Automatic transplanter, compared with semi-automatic transplanting machine, can automatically complete the whole

\section{Received date: 2019-10-15 Accepted date: 2020-05-13}

Biographies: Bingliang Ye, $\mathrm{PhD}$, Professor, research interests: agricultural machinery design, Email: zist_ybl@zstu.edu.cn; Gongjun Zeng, PhD candidate, research interests: agricultural machinery design, Email: 15902775059@ 163.com; Bin Deng, Master candidate, research interests: agricultural machinery design, Email: tada9527@163.com; Chiulan Yang, PhD candidate, research interests: agricultural machinery design, Email: chiulan0913@gmail.com; Jikun Liu, Master, research interests: agricultural machinery design, Email: 916004321@qq.com.

*Corresponding author: Gaohong Yu, PhD, Professor, research interests: agricultural machinery design. Faculty of Mechanical Engineering and Automation, Zhejiang Sci-Tech University, Hangzhou 310018, China. Tel: +86-13093730475, Email: yugh@zstu.edu.cn. transplanting process of seedling pick-up and planting, which has the advantages of good transplanting quality, high transplanting efficiency and low production cost ${ }^{[2]}$. Automatic transplanting mechanism is the core working part that determines the quality and efficiency of transplanting machine, in which the seedling planting mechanism has been developed relatively mature, and the seedling pick-up mechanism is the technical bottleneck that restricts the development of automatic transplanting machine, so it becomes the research and development trend and focus for automatic transplanter ${ }^{[3-5]}$. European and American countries started research on automatic transplanter technology early. Thus, some automatic transplanting machines have been well promoted to be used in the seedling transplanting of big fields. The seedling pick-up mechanism used in Ferrari Futura series and Pearson automatic transplanter of Italian and the UK adopts the seedling ejection rod to push out the rows of seedlings or once take out a row of seedlings by the seedling pick-up claws from the plug tray. The success ratio of seedling pick-up is very high (more than 120 plants per minute per row), but the transplanters are expensive, complicated and not easy to maintain ${ }^{[6]}$. Shaw L N. ${ }^{[7,8]}$ in the United States put forward an ejection-type seedling pick-up mechanism which used pneumatic ejector to push out plug seedlings and coordinated with belt conveyor and spatial link mechanism to realize tomato and pepper plug seedling transplanting with high transplanting efficiency and success ratio. Armstrong et al. ${ }^{[9]}$ designed a seedling pick-up mechanism of 
seedling- pushing-rod type that could provide plug seedling for seedling planting mechanism in order and realize automatic transplanting. Its structure is complex and transplanting efficiency is low. Asian countries as Japan and South Korea also attach great importance to automatic transplanter research ${ }^{[10-14]}$. Naokatsu et al. ${ }^{[1]]}$ invented a seedling pick-up mechanism composed of a gear train and link-slideway which had been applied in actual production. Its seedling pick-up efficiency is not high enough (about 50 plants per minute per row) and the slideway is easy to wear. Choi et al. ${ }^{[13]}$ proposed a seedling pick-up mechanism of crank-guide rod-slideway type with simple structure. Its seedling pick-up efficiency is low (about 30 plants/min) and the slideway is prone to wear. Prasanna $\mathrm{K}$ et al. ${ }^{[14]}$ also proposed a kind of paper pot seedling pick-up device in which the horizontal slat-type chain conveyor was used as feeding conveyor and horizontal pusher type chain conveyor was used as metering conveyor. The transplanting quality of the machine is good, but the transplanting efficiency is still low ( 32 plants/min). In General, the transplanting machines designed by European and American countries have high success ratio of seedling pick-up and are suitable for transplanting in large fields, but they mostly have the problems of complicate structure and high prices, and are difficult to be fully used in China. Asian countries as Japan, South Korea and India have developed some seedling pick-up mechanisms according to the actual seedling transplanting of their countries, but due to their structural limitation, the efficiency of seedling pick-up is still not high enough.

In China, it is not long to study automatic seedling pick-up mechanism that has not been applied. Jin et al. ${ }^{[15,16]}$ proposed a combined type seedling pick-up mechanism of geared five-bar with low seedling pick-up efficiency. Yin et al. ${ }^{[17]}$ designed a seedling pick-up device that could control the opening and closing of the seedling pick-up claw by slideway (grooved cam) to complete the operations of the seedling pick-up and pushing, but the rigid impact of the device is easy to cause plug seedlings to fall during seedling transportation. Zhang et al. ${ }^{[18]}$ proposed a pointer clamping type transplanting claw mechanism based on pneumatic technology. Its transplanting success ratio is low (only $81.5 \%$ ) and it is unsuitable for high-speed transplanting. In recent years, $\mathrm{Yu}$ et al. in the Agricultural Machinery Institute of Zhejiang Sci-Tech University in China, have studied much on rotary pick-up mechanism for dryland plug seedling. Yu et al. and $\mathrm{Ye}$ et al. ${ }^{[19-24]}$ proposed a seedling pick-up mechanism of planetary gear train with incomplete non-circular gear transmission which realized non-uniform intermittent transmission. Zhao et al. ${ }^{[25,26]}$ also proposed a seedling pick-up mechanism of a second-order free noncircular planetary gear system with non-uniform continuous transmission. The Chinese researchers mainly turned to the development of automatic plug seedling pick-up mechanism, but they are mostly in the experimental stage for these years. At present, there is still no efficient seedling pick-up mechanism applied in the automatic transplanting machine for dryland plug seedlings, suitable for large-scale promotion and application of plug seedling transplanting model in China.

Ye et al. $^{[27]}$ and $\mathrm{Yu}$ et al. ${ }^{[28]}$ proposed a seedling pick-up mechanism of planetary gear train with combined non-circular gears of non-uniform continuous transmission. Through the seedling pick-up tests, the mechanism has a good success ratio of seedling pick-up (93.8\%) under a relatively high seedling efficiency (60 plants per minute per row), but there are still three main problems: Firstly, insufficient seedling pick-up depth leads to low success ratio (only $83.6 \%$ ) when the rotation speed of the mechanism increases to $50 \mathrm{r} / \mathrm{min}$ (the seedling pick-up efficiency is 100 plants per minute per row). Secondly, the seedling pick-up angle is a little large (above $50^{\circ}$ ), which also reduces the success ratio of seedling pick-up. Thirdly, during the process of seedling transportation, the minimum distance between the two seedling pick-up arms is a little small, which results in slight interference between the seedling bowl and the end of the other seedling pick-up arm. In this paper, a rotary seedling pick-up mechanism of planetary gear train with combined type gears of incomplete denatured-eccentric-circular and non-circular gears was proposed while the incomplete eccentric circular gear in the original mechanism was denature-treated. The kinematics analysis and modeling of the seedling pick-up mechanism were carried out, and the mechanism parameters were optimized by using the human-computer interaction optimization method. Some other studies on the mechanism were conducted, including development of three-dimentional parametric design system, virtual motion simulation, high-speed camera kinematics tests and seedling pick-up tests.

\section{Transplanting scheme for vegetable plug seedling}

In this paper, the plug seedling tray with $8 \times 16$ cells is adopted for transplanting vegetable plug seedling in which the top and bottom of each cell are squares of $31 \mathrm{~mm} \times 31 \mathrm{~mm}$ and $17 \mathrm{~mm} \times$ $17 \mathrm{~mm}$, respectively, the cell depth is $44 \mathrm{~mm}$, and the center distance between the two adjacent cells is $36.5 \mathrm{~mm}$. The plug seedling tray used for mechanical transplanting and the cultivated vegetable plug seedlings was shown in Figure 1. During transplanting operation, the position of vegetable plug seedling is controlled by seedling delivery devices of longitudinal and transverse direction. The rotary plug seedling pick-up mechanism extracts the plug seedlings from the plug seedling tray shown in Figure 1, and pushes them into the duckbill-type planting mechanism developed by our research team while they are transported to the seedling pushing position. After the plug seedlings fall into the hole which the planting mouth has been opened, the covering wheel covers the soil and then the transplanting operation is completed.

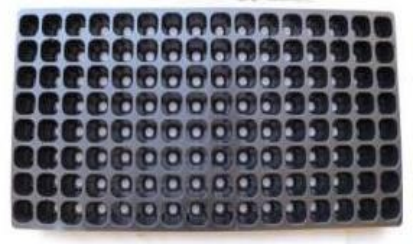

a. Plug seedling tray

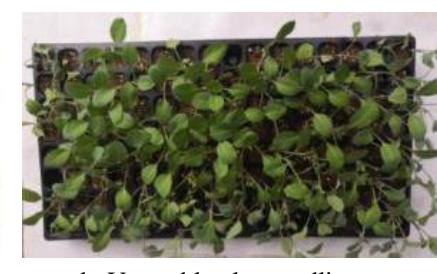

b. Vegetable plug seedlings
Figure 1 Plug seedling tray and vegetable plug seedlings for transplanting

As shown in Figure 2, the rotary seedling pick-up mechanism is composed of a planetary gear train (driving mechanism) and two seedling pick-up arms (executive part). During the rotation of the seedling pick-up mechanism, the cusp $H$ of the seedling pick-up arm forms a closed trajectory $A B C D E F A$, and the posture of the seedling pick-up arm should be well controlled while the seedlings are extracted and pushed. The working process of the rotary seedling pick-up mechanism can be divided into four stages of seedling pick-up, seedling transportation, seedling pushing and return stroke, which are corresponding to the trajectory of $A B C$, $C D E, E F$ and $F A$, respectively. 


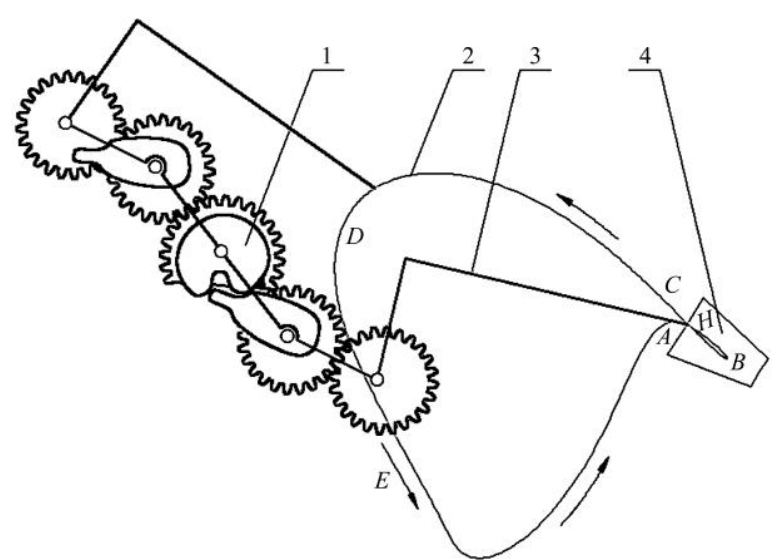

1. Planetary gear train 2. Motion trajectory 3.Seeding pick-up arm 4. Plug seedling tray

Figure 2 Operation scheme of the seedling pick-up mechanism

\section{Kinematics model of rotary seedling pick-up mechanism}

The rotary seedling pick-up mechanism of planetary gear train with combined type gears of incomplete non-circular and denatured-eccentric-circular gears is centro symmetric with the sun gear. It consists a combined gear composed of an incomplete denatured-eccentric-circular gear and a concave tooth non-circular gear (sun gear), two combined gears composed of non-circular gear and convex tooth non-circular gear (middle gears), two planetary non-circular gears, planetary carrier and two seedling pick-up arms. The sun gear is fixed with the frame and the planetary carrier rotates counterclockwise as driving link. The transmission of the sun gear and the middle gear is a transmission mechanism of combined incomplete denatured-eccentric-circular and non-circular gear to achieve non-uniform continuous transmission. A combined mechanism of a cam-rocker mechanism and a double rocker-slider mechanism is adopted in the seedling pick-up arm to control the opening and closing of the seedling clamping board to realize the actions of seedling pick-up and pushing. The shell of the seedling pick-up arm is fixed with the planetary gear through the shaft of the planetary gear, and the cam is fixed with the planetary carrier and rotates with it. The kinematics analysis of the seedling pick-up mechanism was conducted and its kinematics model was established ${ }^{[27-30]}$.

The motion diagram of one side of the seedling pick-up mechanism of planetary gear train with combined type gears of incomplete denatured-eccentric-circular and non-circular gear is shown in Figure 3, among which the initial position of the seedling pick-up mechanism is shown in Figure $3 \mathrm{a}$, and the position after the planetary carrier is rotated counterclockwise by an angle $\varphi_{1}$ is shown in Figure 3b. In the mechanism, the first-stage transmission is alternately meshed by two pairs of gear transmission of the incomplete denatured-eccentric-circular gear 1 and the middle non-circular gear 4, and the concave tooth non-circular gear 2 and the convex tooth non-circular gear 3; the second-stage transmission is meshed by the middle non-circular gear 4 and the planetary non-circular gear 6 .

The rectangular coordinate system $O x y$ shown in Figure 3 was established. Points $O_{1}, O_{2}$ and $O_{3}$ are the rotation centers of the planetary carrier, the middle gear and the planetary gear, respectively. Points $I$ and $J$ are the meshing points between the sun gear and the middle gear, and the middle gear and the planetary gear, respectively. $\varphi_{0}$ and $\delta_{0}$ are the initial installation angle and corner angle of the planetary carrier, respectively. $\alpha_{0}$ is the installation angle of the seedling pick-up arm. $\quad \beta$ is the central angle of the pitch-curve of the toothed part of the incomplete denatured-eccentric-circular gear $1 . \quad \alpha$ is the center angle corresponding to the partial pitch-curve of the middle non-circular gear 4 meshing with the incomplete denatured-eccentric-circular gear 1. $R_{1}, R_{2}$ and $R_{3}$ are the radius vectors of the pitch-curves of the incomplete denatured-eccentric-circular gear 1 , the middle non-circular gear 4 and the planetary non-circular gear 6, respectively. $\quad R_{4}$ and $R_{5}$ are the radius vectors of the concave tooth non-circular gear 2 and the convex tooth non-circular gear 3 , respectively. $\varphi_{1}$ is the angular-displacement of the planetary carrier 5. $\varphi_{2}$ is the angular displacement of the middle gear rotating counterclockwise. $\varphi_{3}$ is the angular displacement of the planetary non-circular gear 6 rotating clockwise. $\quad e, k, R$ and $\theta$ are the eccentric distance, eccentricity, radius and initial angular-displacement of the incomplete denatured-eccentric circle, respectively. $\quad a_{1}$ and $a_{2}$ are the center distance of the first-stage gear transmission and the second-stage gear transmission of the seedling pick-up mechanism, respectively.

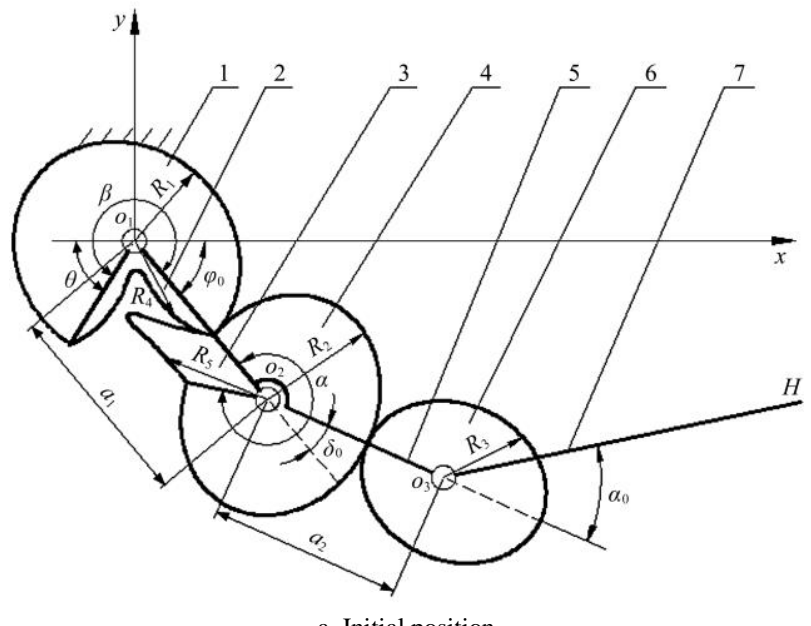

a. Initial position

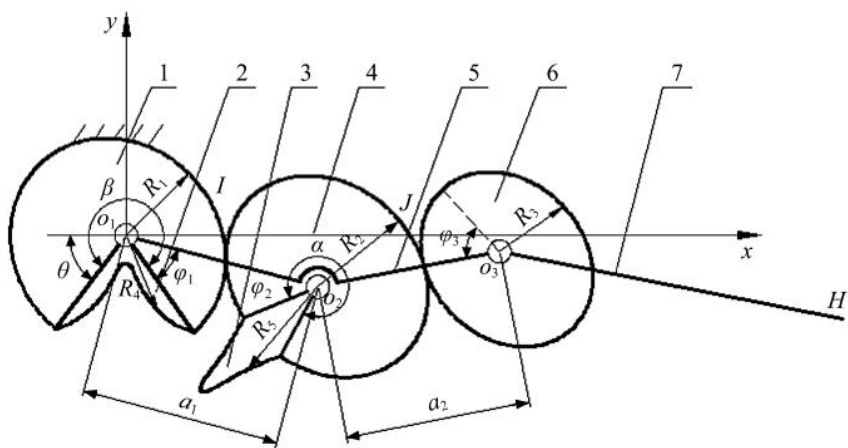

b. Position after the planetary carrier is rotated counterclockwise by an angle $\varphi_{1}$ 1. Incomplete denatured-eccentric-circular gear (sun gear) 2. Concave tooth non-circular gear 3. Convex tooth non-circular gear 4. Middle non-circular gear 5. Planetary carrier 6. Planetary non-circular gear 7. Seedling pick-up arm

Figure 3 Motion diagram of the rotary seedling pick-up mechanism of planetary gear train with combined type gears of incomplete denatured-eccentric-circular and non-circular gears

3.1 Design of the pitch-curves of incomplete denaturedeccentric-circular gear and middle non-circular gear

The meshing pitch-curve length of the incomplete denatured-eccentric-circular gear 1 and the middle non-circular gear 4 should be equal, thus when $\varphi_{1}=\beta, \varphi_{2}=\alpha$, the following equation is obtained:

$$
\alpha=\int_{0}^{\beta} \frac{R_{1}\left(\varphi_{1}\right)}{R_{2}\left(\varphi_{2}\right)} d \varphi_{1}
$$


where,

$$
\begin{aligned}
& R_{1}\left(\varphi_{1}\right)= \\
& \begin{cases}e \cos \left[m_{11}\left(\varphi_{1}+\theta\right)\right]+\sqrt{R^{2}-e^{2} \sin ^{2}\left[m_{11}\left(\varphi_{1}+\theta\right)\right]}, \quad 0 \leq \varphi_{1} \leq \frac{\pi}{2 m_{11}}-\theta \\
e \cos \left[m_{12}\left(\varphi_{1}+\theta\right)\right]+\sqrt{R^{2}-e^{2} \sin ^{2}\left[m_{12}\left(\varphi_{1}+\theta\right)\right]}, \quad \frac{\pi}{2 m_{11}}-\theta \leq \varphi_{1} \leq \beta\end{cases}
\end{aligned}
$$

where, $m_{11}$ is the denatured coefficient of the incomplete denatured-eccentric-circular gear 1 .

where, $m_{12}=\frac{m_{11}}{2 m_{11}-1}$.

Assuming $\lambda=m_{11}\left(\varphi_{1}+\theta\right), \mu=m_{12}\left(\varphi_{1}+\theta\right)$, using Equations (1) and (2), the following equation is obtained:

$$
\begin{gathered}
\alpha=\int_{0}^{\frac{\pi}{2 m_{11}}-\theta} \frac{1-k^{2}}{\frac{a_{1}}{R}\left(\sqrt{1-k^{2} \sin ^{2} \lambda}-k \cos \lambda\right)-\left(1-k^{2}\right)} d \varphi_{1}+ \\
\int_{\frac{\pi}{2 m_{11}}-\theta}^{\beta} \frac{1-k^{2}}{\frac{a_{1}}{R}\left(\sqrt{1-k^{2} \sin ^{2} \mu}-k \cos \mu-\left(1-k^{2}\right)\right.} d \varphi_{1}
\end{gathered}
$$

where, $k=e / R$.

When the parameters $\alpha, \beta, e, R, \theta$ and $m_{11}$ are determined, the center distance of the first-stage gear transmission of the seedling pick-up mechanism $a_{1}$ can be calculated out according to Equation (3).

The radius vector of the pitch-curve of the middle non-circular gear 4 meshing with the incomplete denatured-eccentric-circular gear 1 is

$$
R_{2}\left(\varphi_{2}\right)=a_{1}-R_{1}\left(\varphi_{1}\right), \quad 0 \leq \varphi_{2} \leq \alpha
$$

3.2 Design of the pitch-curves of the concave tooth non-circular gear and the convex tooth non-circular gear, the planetary non-circular gear

The transmission ratio function $i_{1}\left(\varphi_{1}\right)$ of the middle non-circular gear 4 and the incomplete denatured-eccentric-circular gear 1 is

$$
\begin{aligned}
& i_{1}\left(\varphi_{1}\right)= \\
& \left\{\begin{array}{l}
\frac{1-k^{2}}{\frac{a_{1}}{R}\left(\sqrt{1-k^{2} \sin ^{2} \lambda}-k \cos \lambda\right)-\left(1-k^{2}\right)}, 0 \leq \varphi_{1} \leq \frac{\pi}{2 m_{11}}-\theta \\
\frac{1-k^{2}}{\frac{a_{1}}{R}\left(\sqrt{1-k^{2} \sin ^{2} \mu}-k \cos \mu\right)-\left(1-k^{2}\right)}, \frac{\pi}{2 m_{11}}-\theta \leq \varphi_{1} \leq \beta
\end{array}\right.
\end{aligned}
$$

When the middle gear composed of the convex tooth non-circular gear 3 and the middle non-circular gear 4 is rotated by one cycle, it should return to the initial installation position. Therefore, the pitch-curve of the concave tooth non-circular gear 2 and the convex non-circular gear 3 should satisfy the following equation:

$$
2 \pi-\alpha=\int_{\beta}^{2 \pi} i_{2}\left(\varphi_{1}\right) d \varphi_{1}
$$

where, $i_{2}\left(\varphi_{1}\right)$ is the transmission ratio function of the gears 2 and 3 , and is calculated out under the conditions of ensuring the smoothness of the gear transmission and the continuity of the change of transmission ratio $i_{1}\left(\varphi_{1}\right)$ and $i_{2}\left(\varphi_{1}\right)$ in one cycle.

According to $\mathrm{Yu}$ et al. ${ }^{[2]}$, the pitch-curve equations for the transmission of the concave tooth non-circular gear 2 and the convex tooth non-circular gear 3 , and the radius vector of the pitch-curves of the middle non-circular gear 4 and the planetary non-circular gear 6 are as follows, respectively.

$$
\begin{gathered}
\left\{\begin{array}{l}
R_{4}=\frac{a_{1}}{1+i_{2}\left(\varphi_{1}\right)} \\
R_{5}=\frac{a_{1} i_{2}\left(\varphi_{1}\right)}{1+i_{2}\left(\varphi_{1}\right)}
\end{array}\right. \\
R_{2}\left(\varphi_{2}\right)=\left\{\begin{array}{l}
a_{1}-R_{1}\left(\varphi_{1}\right), \quad 0 \leq \varphi_{2} \leq \alpha \\
c_{0}+c_{1} \varphi_{2}+c_{2} \varphi_{2}^{2}+c_{3} \varphi_{2}^{3}, \quad \alpha \leq \varphi_{2} \leq 2 \pi
\end{array}\right. \\
R_{3}\left(\varphi_{3}\right)=a_{2}-R_{2}\left(\varphi_{2}+\pi-\delta_{0}\right)
\end{gathered}
$$

where, the coefficients $c_{0}, c_{1}, c_{2}$, and $c_{3}$ are calculated out under the condition of ensuring the completeness, smoothness and continuity of the pitch-curve of the middle non-circular gear 4 in one cycle.

3.3 Displacement analysis of the cusp of the seedling pick-up arm

According to the geometric relationship of the seedling pick-up mechanism, the relative displacement equation of the cusp $H$ of the seedling arm is obtained as follows:

$$
\left\{\begin{aligned}
X_{H}= & a_{1} \cos \left(\varphi_{0}+\varphi_{1}\right)+a_{2} \cos \left(\varphi_{0}+\varphi_{1}+\delta_{0}\right)+ \\
& S \cos \left(\varphi_{0}+\varphi_{1}+\delta_{0}+\alpha_{0}+\varphi_{3}\right) \\
Y_{H}= & a_{1} \sin \left(\varphi_{0}+\varphi_{1}\right)+a_{2} \sin \left(\varphi_{0}+\varphi_{1}+\delta_{0}\right)+ \\
& S \sin \left(\varphi_{0}+\varphi_{1}+\delta_{0}+\alpha_{0}+\varphi_{3}\right)
\end{aligned}\right.
$$

where, $S$ is the distance between the cusp of the seedling pick-up arm and the rotation center of the planetary non-circular gear.

\section{Parameter optimization of rotary seedling pick-up mechanism}

The human-computer interaction optimization method can effectively realize the parameters optimization of rotary plug seedling pick-up mechanism for vegetable automatic transplanter which is the complex multi-objective optimization problem with the characteristics of nonlinearness, fuzzyness and strong coupling. The optimization method was used to realize the parameter optimization of the mechanism according to four steps of mathematical modeling, developing optimization software, analyzing the influence of variables on objectives, and optimization results analysis ${ }^{[31-34]}$.

\subsection{Optimization objectives and design variables of seedling pick-up mechanism}

In order to meet the requirements of mechanical pick-up for vegetable plug seedlings and improve the problems of the original mechanism ${ }^{[28]}$, the main optimization objectives of the seedling pick-up mechanism about the motion trajectory, the posture of the seedling pick-up arm were determined as follows:

1) The length of the seedling pick-up trajectory in the tray should be longer than $35 \mathrm{~mm}$;

2) The seedling pick-up trajectory should form a slender ring and the width of the ring should be less than $5 \mathrm{~mm}$;

3) The seedling pushing angle of the mechanism should exceed $50^{\circ}$.

In addition, there also should be no motion interference between the two seedling pick-up arms or between the arms and the plug seedling tray.

Through kinematic analysis of the seedling pick-up mechanism the following design variables were selected: the central angle corresponding to the pitch-curve of the toothed part of the incomplete denatured-eccentric-circular gear $\beta$; the radius, eccentric distance and denatured coefficient of the incomplete denatured eccentric circle $R, e$ and $m_{11}$; the central angle corresponding to the pitch-curve of the meshing part of the middle non-circular gear with the incomplete denatured-eccentric-circular 
gear $\alpha$; the initial installation angle and corner angle of the planetary carrier $\varphi_{0}$ and $\delta_{0}$; the initial angular-displacement of the incomplete denatured eccentric circle $\theta$; and the distance between the cusp of the seedling pick-up arm and the rotation center of the planetary non-circular gear $S$.

\subsection{Optimization and results analysis of seedling pick-up} mechanism

It is benefit for improving optimization efficiency to analyze the influence of the design variables on the motion trajectory. In this paper, the influence of the denatured coefficient of the incomplete denatured-eccentric-circular gear $m_{11}$ was analyzed because many researches were already conducted on the influence analysis of the other variables ${ }^{[29]}$. The denatured coefficient $m_{11}$ affects the trajectory of the seedling pick-up section and the trajectory height by adjusting the peak position of the transmission ratio. As shown in Figure 4, when $m_{11}$ increased from 0.9 to 1.1, the trajectory height increased from $166.45 \mathrm{~mm}$ to $204.12 \mathrm{~mm}$. When $m_{11}$ was equal to 0.9 , the width of the ring was $3.8 \mathrm{~mm}$ and the length of the seedling pick-up trajectory of approximate line segment was long, which is benefit to seedling pick-up. When it was equal to 1 or 1.1 , no ring was formed, which is not suitable for seedling pick-up.

The human-computer interaction analysis and optimization software based on the visualization development platform of Visual
Basic 6.0 for the design of the seedling pick-up mechanism was developed, and its main interface is shown in Figure 5, in which region 1 is the software function selection area. By using the software, the parameters of the mechanism are input or adjusted in region 3 to simulate the motion of the mechanism, and to analyze the influence of the design variables on the mechanism trajectory and the angular-displacement of seedling pick-up arm. The schematic diagram and motion trajectory of the mechanism are displayed in real time and the motion interference is checked. The tooth profile of the non-circular gear is designed. In region 4, real-time output the results of the seedling pick-up angle, the seedling pushing angle and their difference of the seedling pick-up mechanism.

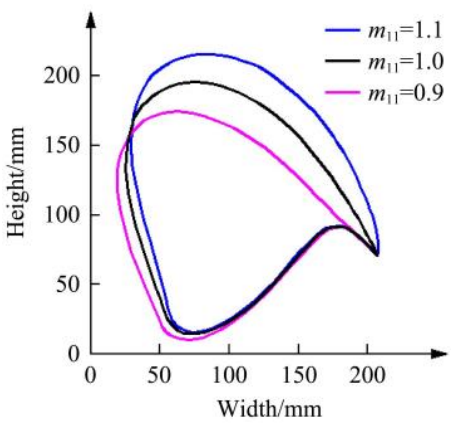

Figure 4 Influence of denatured coefficient on the trajectory

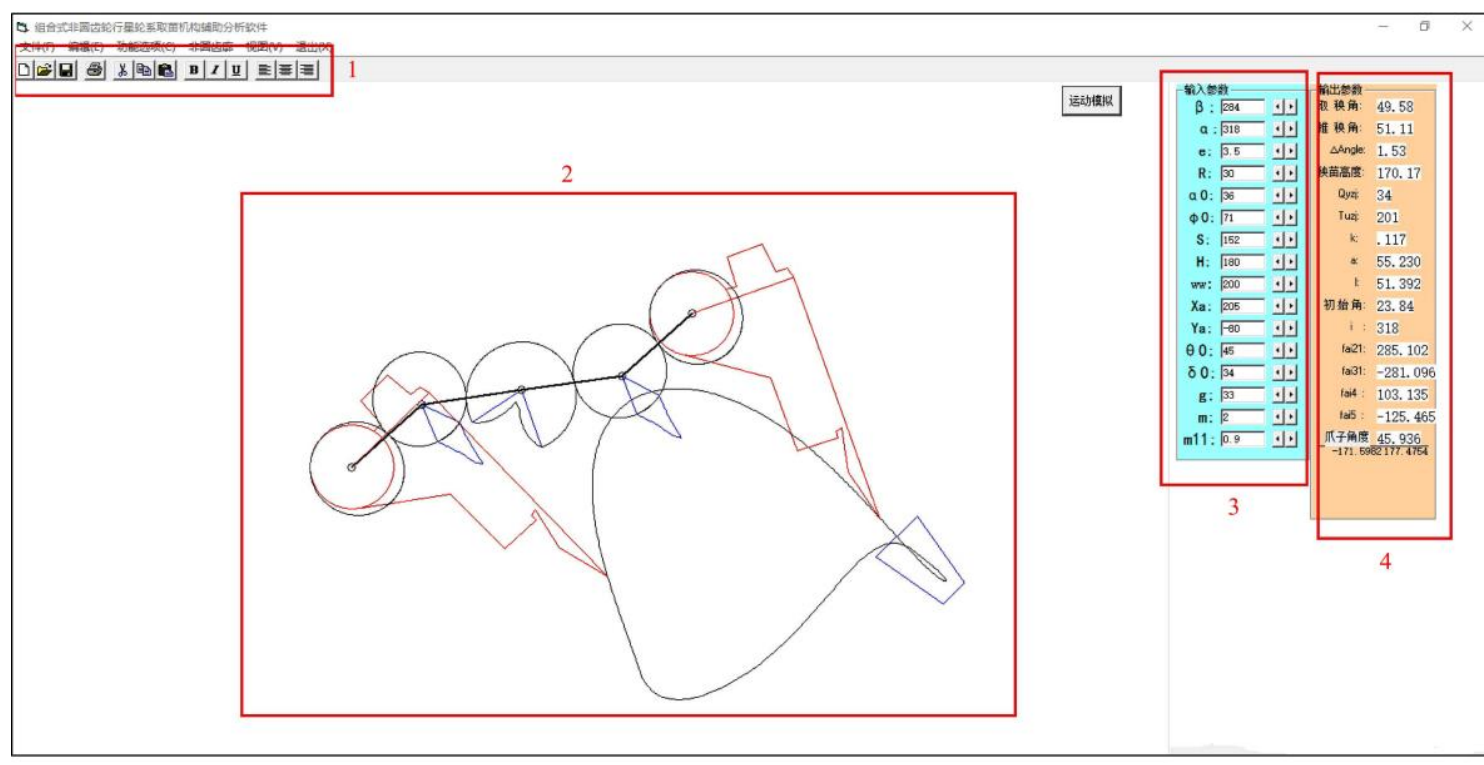

1. Menu area 2. Graphic-display area 3. Parameter-input area 4. Results-output area

Figure 5 Main interface of parameter-optimization software for the seedling pick-up mechanism

According to human-computer interaction optimization, a set of parameters of the seedling pick-up mechanism satisfying the optimization objectives were obtained: $\beta=286^{\circ}, \alpha=318^{\circ}, e=3.5 \mathrm{~mm}$, $R=30 \mathrm{~mm}, m_{11}=0.9, \varphi_{0}=71^{\circ}, \delta_{0}=34^{\circ}, \theta=30^{\circ}$ and $S=152 \mathrm{~mm}$. The parameters of the middle non-circular gear were $c_{0}=65.48, c_{1}=$ $-11.20, \quad c_{2}=0.10$ and $c_{3}=0.11$. The center distance of the first-stage transmission and the second-stage transmission were $a_{1}=55.47 \mathrm{~mm}$ and $a_{2}=51.812 \mathrm{~mm}$, respectively.

After parameter optimization of the mechanism, the motion trajectory of the mechanism was obtained, as shown in Figure 6. The trajectory of the seedling pick-up section forms a slender ring whose width is $3.8 \mathrm{~mm}$. The trajectory length in the seedling tray is $38.4 \mathrm{~mm}$, and the trajectory of the seedling pick-up section is nearly perpendicular to plug seedling tray. The seedling pushing angle is approximately $52.05^{\circ}$, and meanwhile, the height of the trajectory is $166.4 \mathrm{~mm}$. Motion simulation of the seedling pick-up mechanism indicates that there is no motion interference in the mechanism. The parameter-optimization results of the seedling pick-up mechanism meet the requirements of the optimization objectives, and the optimized seedling pick-up mechanism meets the requirements of the vegetable plug seedling transplanting.

The comparison of motion trajectories and relevant parameters of the seedling pick-up mechanism in this paper and the original one in literature [28] are shown in Figure 6 and listed in Table 1, respectively.

According to Figure 6 and Table 1, the seedling mechanism in this paper has the following advantages:

1) The trajectory length in the seedling tray increases from $30.4 \mathrm{~mm}$ to $38.4 \mathrm{~mm}$, meaning the seedling pick-up claws can insert deeper into the tray and be easier to clamp plug seedlings during the process of seedling pick-up, which is conducive to improve the success ratio of seedling pick-up of the new seedling 
pick-up mechanism.

2) The seedling pick-up angle decreases from $50.01^{\circ}$ to $45.21^{\circ}$, meaning that the seedling pick-up claws are almost perpendicular to the plug seedling tray during the seedling pick-up stage, which is conducive to avoid the interference between the seedling pick-up claws and the seedling tray, and also improve the success ratio of seedling pick-up.

3) The distance between the easily interfered positions increases from $21.45 \mathrm{~mm}$ to $23.74 \mathrm{~mm}$ and meanwhile the trajectory length in the seedling tray also increases, which are conducive to avoid the motion interference between the seedling bowl and the end of the other seedling pick-up arm.

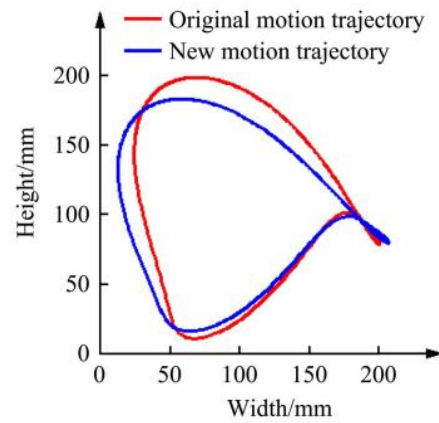

Figure 6 Motion trajectory comparison between new seedling pick-up mechanism and the original one

Table 1 Relevant parameters comparison between the seedling pick-up mechanism in this paper and the original one

\begin{tabular}{lcc}
\hline & $\begin{array}{c}\text { New seedling pick-up } \\
\text { mechanism }\end{array}$ & $\begin{array}{c}\text { Original seedling } \\
\text { pick-up mechanism }\end{array}$ \\
\hline $\begin{array}{l}\text { The trajectory length in the } \\
\text { seedling tray/mm }\end{array}$ & 38.4 & 30.4 \\
$\begin{array}{l}\text { The distance between the easily } \\
\text { interfered positions } / \mathrm{mm}\end{array}$ & 23.74 & 21.45 \\
$\begin{array}{l}\text { Seedling pick-up angle } /\left(^{\circ}\right) \\
\text { Seedling pushing angle } /\left(^{\circ}\right)\end{array}$ & 45.21 & 50.01 \\
\hline
\end{tabular}

\section{Virtual simulation and tests of rotary seedling} pick-up mechanism

\subsection{Virtual simulation of seedling pick-up mechanism}

5.1.1 Development of the three-dimensional parametric design system

The three-dimensional parametric design system developed for the seedling pick-up mechanism of combined non-circular gear transmission can not only automatically generate the three-dimensional solid model of the seedling pick-up mechanism, but also directly derive the two-dimensional drawings of the corresponding parts of the mechanism. What's more, it can also be applied to the parametric design of the rice plug seedling transplanting mechanism of the similar configuration through parameters adjustment, which is conducive to shorten design cycle of mechanisms.

The 3D software NX10.0 was taken as the development platform and the block UI style editor module was used to customize user interface, and secondary development of NX10.0 was completed by using $\mathrm{C}++$ language, then the three-dimensional parametric design system for the seedling pick-up mechanism of combined non-circular gear transmission was developed, as shown in Figure 7. In the parametric design system, twelve main parameters were taken to express the three-dimensional model of the seedling pick-up mechanism, including the central angle corresponding to the pitch-curve of the toothed part of the incomplete denatured-eccentric-circular gear $\beta$; the radius, eccentric distance and denatured coefficient of the incomplete denatured eccentric circle $R, e$ and $m_{11}$; the central angle corresponding to the pitch-curve of the meshing part of the middle non-circular gear with the incomplete denatured-eccentric-circular gear $\alpha$; the initial installation angle and corner angle of the planetary carrier $\varphi_{0}$ and $\delta_{0}$; the initial angular-displacement of the incomplete denatured eccentric circle $\theta$; the installation angle of seedling pick-up arm $\alpha_{0}$; the gear module and width $m$ and $b$; and the radius of the sun gear shaft $r$. Input the main design parameters through the user interface, the 3D model of the seedling pick-up mechanism will be automatically built and displayed on the interface.

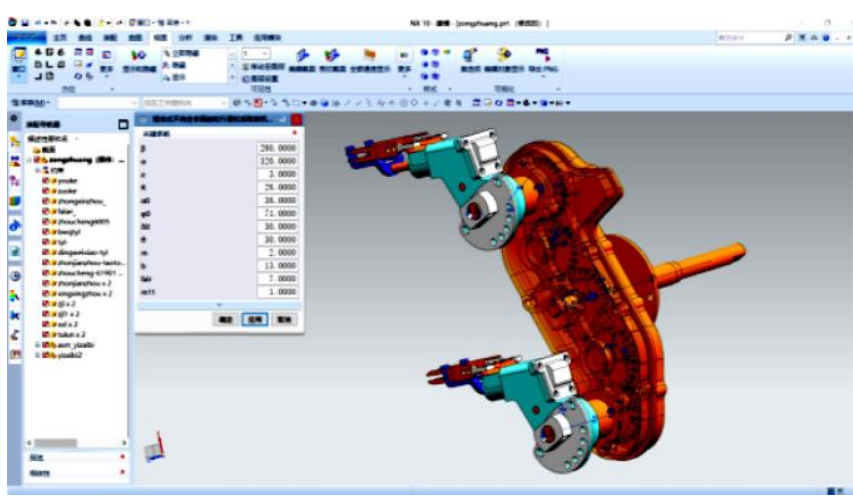

Figure 7 Parametric design interface of the seedling pick-up mechanism

\subsubsection{Results analysis of virtual simulation}

The 3D solid model of the seedling pick-up mechanism automatically generated was imported into ADAMS2013, and the virtual prototype of the seedling pick-up mechanism shown in Figure 8 was established for motion simulation. The motion trajectory and angular-displacement curve of seedling pick-up arm obtained through virtual simulation were compared with theoretical analysis, respectively, which verified the correctness of theoretical model and design results of seedling pick-up mechanism.

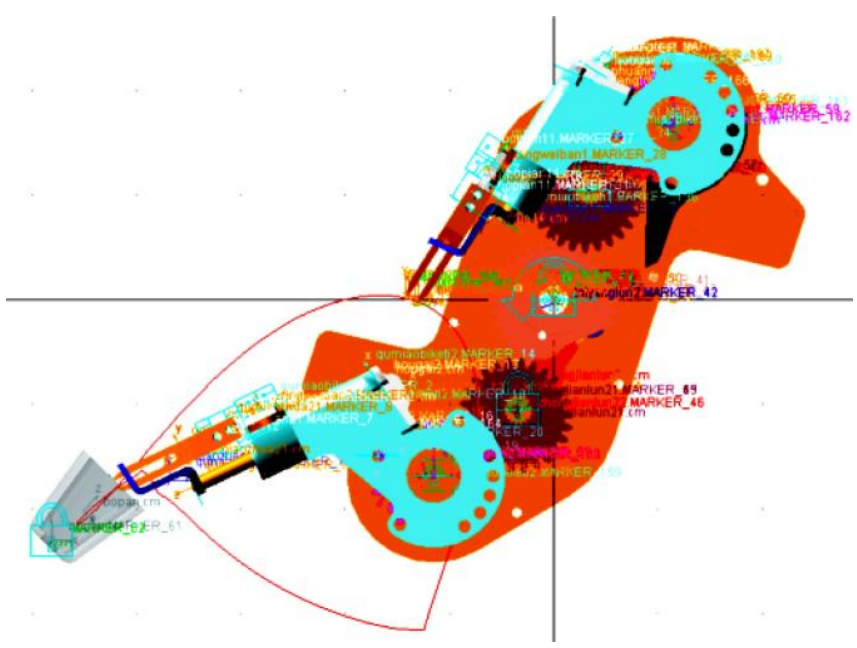

Figure 8 Virtual prototype simulation of seedling pick-up mechanism

The comparison between virtual simulation trajectory and theoretical analysis trajectory was shown in Figure 9. The motion trajectory of virtual simulation was shown in Figure 9a where the length and width of the ring of the seedling pick-up section trajectory are approximately $38.15 \mathrm{~mm}$ and $2.8 \mathrm{~mm}$, respectively, which are near to the theoretical results of $38.4 \mathrm{~mm}$ and $3.8 \mathrm{~mm}$, respectively. The shape and height of the two motion trajectories are basically the same, but the $F A$ section of the simulation 
trajectory is slightly different to that of the theoretical trajectory because the concave-convex tooth non-circular gear pairs are designed as cam-like by graphic method. However, the difference is the return section trajectory, no influences on the seedling pick-up and pushing operations of the mechanism.

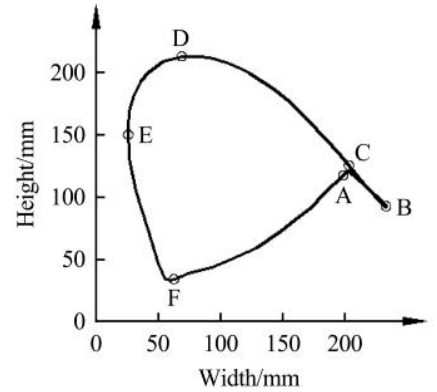

a. Simulation trajectory

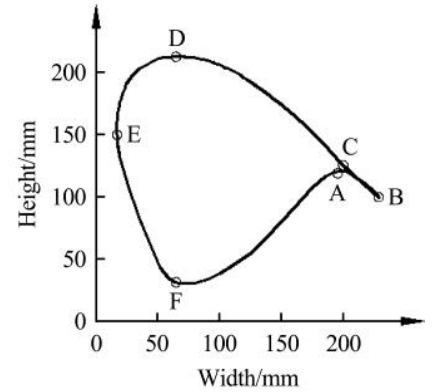

b. Theoretical trajectory

Figure 9 Comparison of simulation and theoretical motion trajectory of seedling pick-up mechanism

As shown in Figures 10a and 10b, the theoretical curve and simulation curve of angular-displacement of the seedling pick-up arm are basically the same. The seedling pushing angles of virtual simulation and theoretical analysis of the seedling pick-up mechanism are $51.67^{\circ}$ and $52.05^{\circ}$, respectively, and the difference between them is only $0.38^{\circ}$.
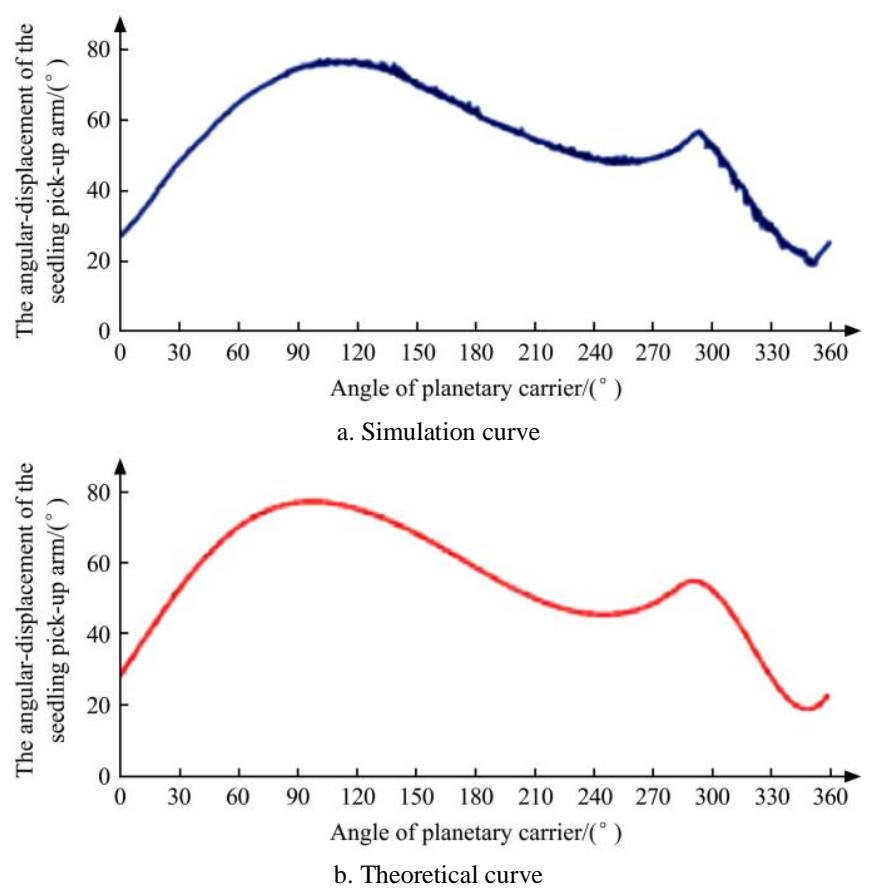

Figure 10 Comparison of angular-displacement curves of seedling pick-up arm through theoretical analysis and virtual simulation

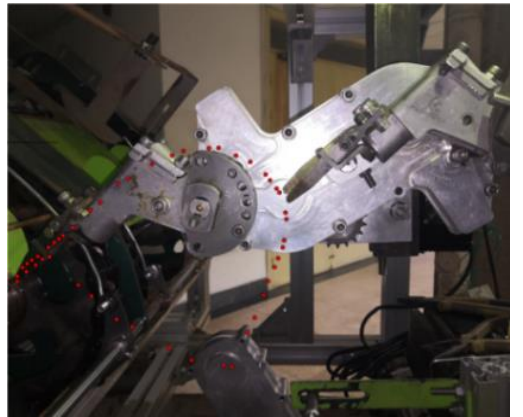

a. Test trajectory

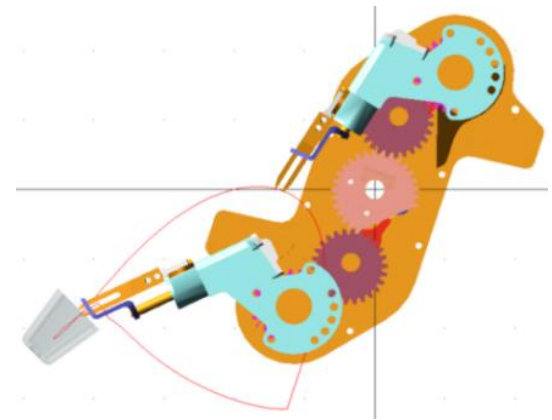

b. Simulation trajectory

\subsection{Bench tests of the mechanism prototype}

The two-dimensional drawings of components of the mechanism, such as non-circular gears, box and shaft, were derived by using the three-dimensional parametric design system of seedling pick-up mechanism. Non-circular gears were manufactured by wire-cutting technology and processed via quenching to improve its strength. Aluminum alloy parts, including gearbox, were manufactured in a machining center, and then the parts were assembled into a physical prototype of the seedling pick-up mechanism. As shown in Figure 11, the mechanism prototype was installed on a self-made test bench, including automatic seedling delivery device, chain drive and power device (servo motor). The high-speed camera kinematics tests and seedling pick-up tests of the mechanism prototype were conducted in the laboratory to study the kinematics characteristics and verify the effect of seedling pick-up.
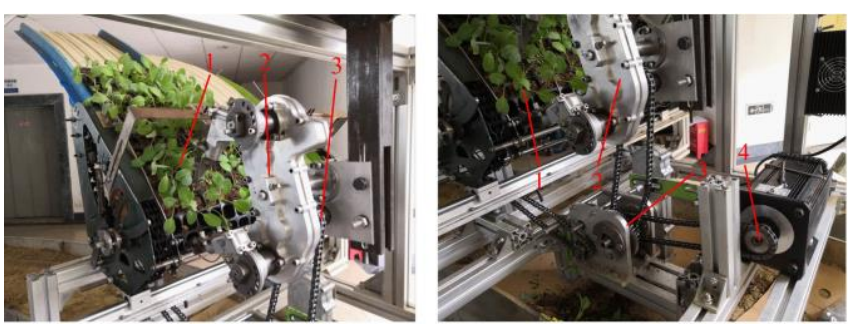

1. Automatic seedling delivery device 2 . Seedling pick-up mechanism 3. Chain drive 4. Power device

Figure 11 Test bench of seedling pick-up mechanism

\subsubsection{Kinematics tests of the mechanism prototype}

The kinematics tests of seedling pick-up mechanism were conducted in the absence of seedlings. Firstly, the cusp of a seedling pick-up arm was marked clearly and the motion trajectory of the marked point was captured with Phantom v5.1 high-speed camera when the photography frequency was set to $370 \mathrm{fps}$. Secondly, test videos were imported into Photoshop for video layer analysis, getting a series of layers and drawing trajectory points one by one. Finally, the motion trajectory of the cusp of the seedling pick-up arm shown in Figure 12a was obtained.

Comparing the test trajectory, simulation trajectory and theoretical trajectory shown in Figures 12a, 12b and 12c, respectively, the results show that the test trajectory is basically consistent with the simulation trajectory, but slightly different to the theoretical trajectory in the return section. The main reason is that concave-convex tooth non-circular gear pairs were designed as cam-like by graphic method, but the difference is the return section trajectory, which would not affect the seedling pick-up and pushing of the mechanism.

During the prototype tests, the mechanism run stably and had no motion interference, indicating that the design of the seedling pick-up mechanism was effective and correct.

Figure 12 Comparison of motion trajectories of seedling pick-up mechanism

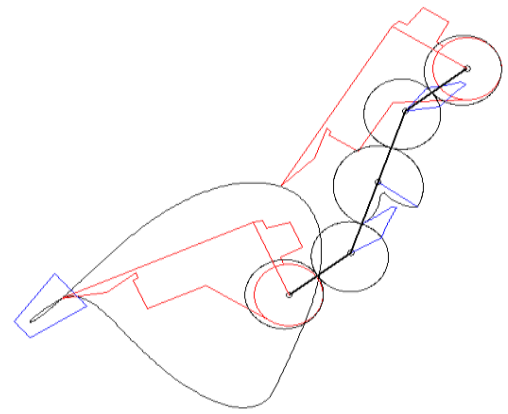

c. Theoretical trajectory 


\subsubsection{Seedling pick-up tests of the mechanism prototype}

In the laboratory, the seedling pick-up tests of the mechanism prototype were carried out. The experimental broccoli seedlings shown in Figure 1 were cultivated by Hangzhou Hongyue Ecological Agriculture Technology Company, with the seedling age of 30-35 d, seedling height of 120-180 mm and moisture content of $50 \%$. The seedling pick-up tests were conducted at the mechanism rotation speeds of $40 \mathrm{r} / \mathrm{min}, 50 \mathrm{r} / \mathrm{min}$, respectively. The number of plug seedlings successfully extracted was recorded, and the success ratio of seedling pick-up was calculated.

As shown in Figure 13, there were three key operations of the seedling pick-up mechanism in one working period, including seedling pick-up, seedling transportation and seedling pushing. The results of seedling pick-up tests are shown in Table 2. The seedling pick-up mechanism has high success ratio of seedling pick-up when it runs at high speed. The success ratio of seedling pick-up is $96.3 \%$ when the mechanism rotation speed is $50 \mathrm{r} / \mathrm{min}$ (the seedling pick-up efficiency is 100 plants per minute per row), which is much higher than the success ratio of seedling pick-up of the mechanism (83.6\%) in literature [28]. Through observing the operation process of the seedling pick-up mechanism and the effect of seedling pushing, the seedling pick-up mechanism solved the problem of the interference between the seedling bowl and the end of the other seedling pick-up arm, and also greatly improved the situations of seedling hanging up and seedling pushing failure. The results of seedling pick-up showed that the novel mechanism in this paper has better performance than the original one in literature [28], and could basically achieve automatic seedling efficiency.

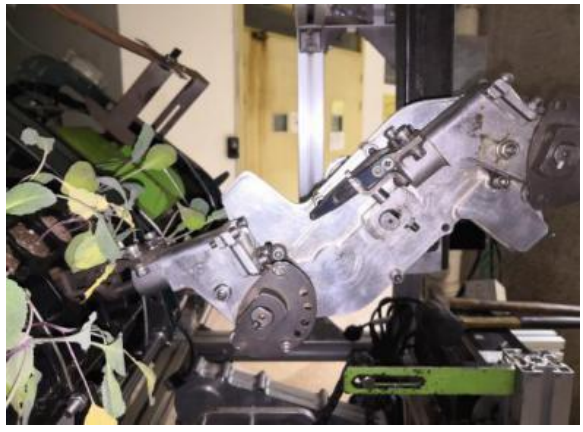

a. Seedling pick-up

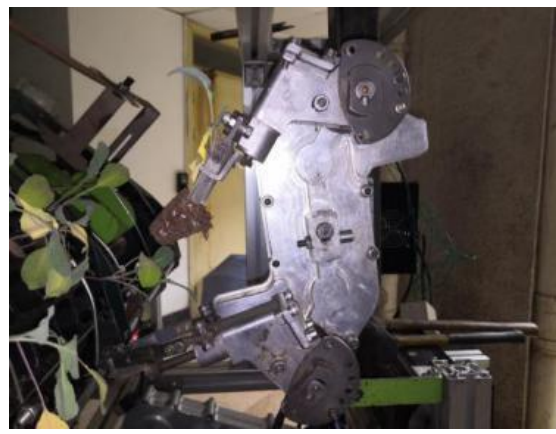

b. Seedling transportation

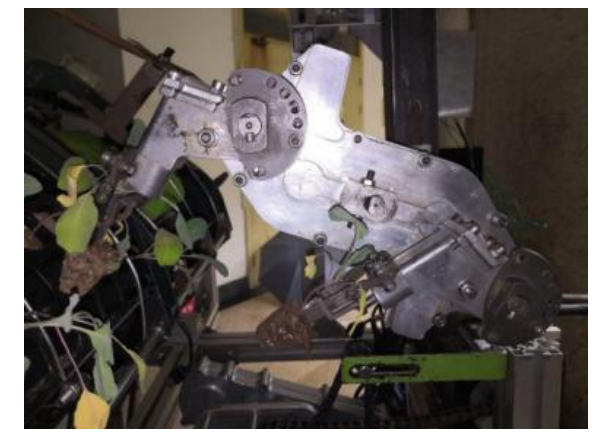

c. Seedling pushing

Figure 13 Three key operations of seedling pick-up mechanism

Table 2 Results of seedling pick-up tests

\begin{tabular}{cccc}
\hline $\begin{array}{c}\text { Rotation } \\
\text { speed/r } \cdot \text { min }^{-1}\end{array}$ & $\begin{array}{c}\text { Total number of } \\
\text { seedlings (plant) }\end{array}$ & $\begin{array}{c}\text { Number of seedlings } \\
\text { successfully extracted (plant) }\end{array}$ & $\begin{array}{c}\text { Success ratio of } \\
\text { seedling pick-up/\% }\end{array}$ \\
\hline 40 & 56 & 50 & 89.29 \\
50 & 54 & 52 & 96.3 \\
\hline
\end{tabular}

\section{Conclusions}

(1) A novel rotary seedling pick-up mechanism of planetary gear train with combined type gears of incomplete denatured-eccentric-circular and non-circular gears for vegetable plug seedling transplanting was studied based on previous researches. Kinematics modeling and analysis of the mechanism was performed.

(2) Through the human-computer interaction analysis and optimization software of the seedling pick-up mechanism developed based on Visual Basic 6.0, a set of parameters of the mechanism meeting design requirements were obtained: $\beta=286^{\circ}$, $\alpha=318^{\circ}, e=3.5 \mathrm{~mm}, R=30 \mathrm{~mm}, m_{11}=0.9, \varphi_{0}=71^{\circ}, \delta_{0}=34^{\circ}, \theta=$ $30^{\circ}, S=152 \mathrm{~mm}$.

(3) The three-dimensional solid model of the seedling pick-up mechanism was generated by using the self-developed threedimensional parametric design system developed based on secondary development of NX10.0 with C++ language, and imported into ADAMS2013 for motion simulation, which verified the correctness of theoretical model and design results of the mechanism.

(4) High-speed camera kinematics tests and seedling pick-up tests were conducted. The tests results indicate that the mechanism has a good trajectory, the success ratio of seedling pick-up $96.3 \%$ is high and the seedling pushing effects are much improved under the high seedling pick-up efficiency of 100 plants per minute per row.
(5) The novel seedling pick-up mechanism solved the main problems of the original one effectively, and had better working performance and high feasibility to be applied in vegetable plug seedling transplanter.

\section{Acknowledgements}

The authors thank the editors and the anonymous reviewers whose constructive comments have notably contributed to the improved quality and clarity of this paper. This article was supported in part by the Zhejiang Provincial Natural Science Foundation of China (Grant No. LZ16E05003), the Natural Key Research and Development Program of China (Project No. 2017YFD0700800), and the Science Foundation of Zhejiang Sci-Tech University (Grant No. 15022011-Y).

\section{[References]}

[1] Chen Y. China vegetable production mechanization development report in 2018. Journal of Chinese Agriculture Mechanization, 2019; 40(4): 1-6, 18. (in Chinese)

[2] Kumar G V P, Raheman H. Vegetable transplanters for use in developing countries-A review. International Journal of Vegetable Science, 2008; 14(3): 232-255.

[3] Yu X, Zhao Y, Chen B, Zhou M, Zhang H, Zhang Z. Current situation and prospect of transplanter. Transactions of the CSAM, 2014; 45(8): 44-53. (in Chinese)

[4] Chen Q, Yun J, Chen Y, Hu H, Gao Q. Development status of vegetable transplanting machinery at home and abroad. Vegetable, 2016; 8: 76-179. (in Chinese)

[5] Chen Y, Cui S, Xiao T, Hu H. Vegetable production Mechanization urgently needs to strengthen agricultural machinery and agronomic integration. Vegetable, 2015; 2: 1-3. (in Chinese)

[6] Cui W, Xu P, Wang H, Li G, Su Y, Song J. Present status and analysis of dry-land auto-transplanting seedling technique. Journal of Agricultural Mechanization Research, 2015; 28: 1-5. (in Chinese)

[7] Shaw L N. Automatic transplanter for vegetables. Proceedings of Florida State Horticultural Society, 1997; 110: 262-263. 
[8] Shaw L N. Removing and handling modular vegetable seedlings from nursery trays. Proceedings of Florida State Horticultural Society, 1999; 112: 153-155.

[9] Armstrong E C, Hanacek W A, Spinetti T. Automatic soil plug loader and feeder. US patent, No. 4443151, 1984.

[10] Tsuga K. Development of fully automatic vegetable transplanter, Japan Agriculture Research Quarterly, 2000; 34(1): 21-28.

[11] Naokatsu I, Shuichi K, Shunro N. Seedling transplanting mechanism of transplanter. Chinese Patent, ZL99118740.7, 2000. (in Chinese)

[12] Kang T G, Kim S W, Kim Y, Keun L S, Hee J, Hyeon J, et al. Analysis of pick-up mechanism for automatic transplanter (I). Journal of Agriculture \& Life Science, 2017; 51(1): 187-192.

[13] Choi W C, Kim D C, Ryu I H, Kim K U. Development of seedling pick-up device for vegetable transplants. Transaction of the ASABE, 2001; 45(1): 13-19.

[14] Prasanna K G V, Raheman H. Development of a walk-behind type hand tractor powered vegetable transplanter for paper pot seedlings. Biosystems Engineering, 2011; 110: 189-197.

[15] Jin X, Li D, Ma H, Ji J, Pang J. Development of single row automatic transplanting device for potted vegetable seedlings. Int J Agric \& Biol Eng, 2018; 11(3): 67-75.

[16] Jin X, Li M, Li D, Ji J, Pang J, Wang J. . Eurasip Journal on Wireless Communications \& Networking, 2018; $1: 178$

[17] Yin W, Hu M, Hu F, Li H. An automatic pick-up mechanism for dry field plug seedlings. Chinese Patent, ZL101536632A, 2009. (in Chinese)

[18] Zhang L, Qiu L, Tian S, Xiang Q. Design of a needle clamping claw for plug seedling transplanting. Journal of Shenyang Agricultural University, 2010; 41(2): 235-237. (in Chinese)

[19] Yu G H, Liu B, Zhao Y, Sun L. Kinematic principle analysis of transplanting mechanism with planetary elliptic gears in automatic vegetable transplanter. Transactions of the CSAM, 2011; 42(4): 53-56. (in Chinese)

[20] Yu G H, Chen Z, Zhao Y, Sun L, Ye B L. Study on vegetable plug seedling pick-up mechanism of planetary gear train with ellipse gears and incomplete non-circular gear. Journal of Mechanical Engineering, 2012; 48(13): 32-39. (in Chinese)

[21] Yu G, Yu T, Ye B, Jia D, Wang L, Hu H. Research on a new planetary gear train mechanism. Journal of Mechanical Engineering, 2013; 49(15): 55-61. (in Chinese)

[22] Yu G H, Yu T, Ye B L, Hu H, Wang L. Design of a rotary plug seedling pick-up mechanism. Journal of Mechanical Engineering, 2015; 51(7): 67-76. (in Chinese)

[23] Yuan X B, Zhang G F, Chen J N, Zhao Y. Development on rice plooted-seedling sequential transplanter. Journal of Zhejiang Sci-Tech
University, 2011; 28(5): 49-53. (in Chinese)

[24] Ye B L, Yu G H, Chen Z, Zhao Y. Kinematics modeling and parameters optimization of seedling pick-up mechanism of planetary gear train and non-circular gear. Transactions of the CSAE, 2011; 27(12): 7-12. (in Chinese)

[25] Zhao X, Cui H Y, Dai L, Chen J N, Ye B L. Kinematic analysis and experimental research on the seedling pick-up mechanism of a second-order free noncircular planetary gear system. Applied Engineering in Agriculture, 2017; 33(2): 169-179.

[26] Zhao X, Shen M, Chen J N. Seedling pick-up mechanism of planetary gear train with two-order general non-circular gears. Transactions of the CSAM, 2014; 45(4): 123-127. (in Chinese)

[27] Ye B L, Jin X, Yu G H, Gao Y. A vegetable seedling pick-up mechanism of planetary gear train with concave tooth- incomplete eccentric circle gear - non-circular gears. Chinese Patent, ZL201610118934.4, 2017. (in Chinese)

[28] Yu Y, Liu J, Ye B L, Yu G H, Jin X, Sun L, et al. Design and experimental research on seedling pick-up mechanism of planetary gear train with combined non-circular gear transmission. Chinese Journal of Mechanical Engineering, 2019; 32: 49.

[29] Jin X J. Optimization design and tests of seedling pick-up mechanism of planetary gear train with combined gear transmission of incomplete eccentric circle gear and non-circular gears. Hangzhou, China: Zhejiang Sci-Tech University, 2017. (in Chinese)

[30] Ye B L, Tang T, Yu G H, Tong J, Yi W M, Zheng Y. Dynamics analysis and experiment seedling pick-up mechanism of planetary gear train with combined non-circular gear transmission. Transactions of the CSAM, 2018; 49(12): 74-82. (in Chinese)

[31] Ye B L, Liu A, Yu G H, Luo C. Parameters optimization with human-computer interaction method and experiment of vegetable seedling pick-up mechanism. Transactions of the CSAM, 2013; 44(2): 57-62. (in Chinese)

[32] Wu C, Zhao Y, Chen J. Optimization design of rice transplanter separating-planting mechanism with visualization human-computer interaction method. Transactions of the CSAM, 2008; 39(1): 46-49. (in Chinese)

[33] Ye B L, Jin X J, Yu G H, Li L, Gao Y, Zhu H. Parameter modification guiding optimization design and tests of a rotary transplanting mechanism for rice plug seedlings. Applied Engineering in Agriculture, 2015; 31(6): 863-873.

[34] Zhao X, Chu M, Ma X, Dai L, Ye B L. Research on design method of non-circular planetary gear train transplanting mechanism based on precise poses and trajectory optimization. Advances in Mechanical Engineering, 2018; 10(12): 1-12. 